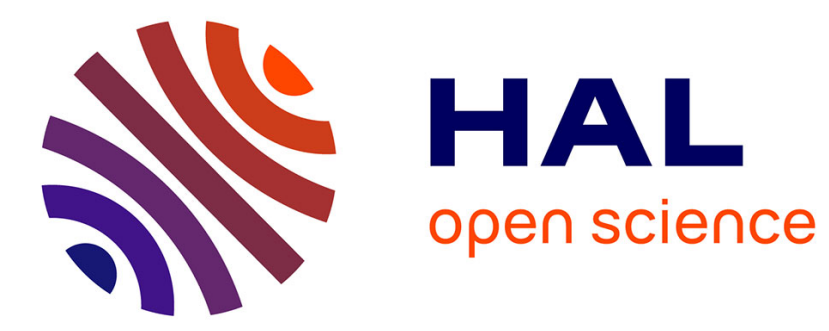

\title{
Linking demographic responses and life history tactics from longitudinal data in mammals
}

\author{
Marlène Gamelon, Jean-Michel Gaillard, Olivier Gimenez, Tim Coulson, \\ Shripad Tuljapurkar, Serge Brandt, Eric Baubet
}

\section{- To cite this version:}

Marlène Gamelon, Jean-Michel Gaillard, Olivier Gimenez, Tim Coulson, Shripad Tuljapurkar, et al.. Linking demographic responses and life history tactics from longitudinal data in mammals. Oikos, 2015, 125, pp.395 - 404. 10.1111/oik.02582 . hal-03499378

\section{HAL Id: hal-03499378 https://hal.science/hal-03499378}

Submitted on 4 Jan 2022

HAL is a multi-disciplinary open access archive for the deposit and dissemination of scientific research documents, whether they are published or not. The documents may come from teaching and research institutions in France or abroad, or from public or private research centers.
L'archive ouverte pluridisciplinaire HAL, est destinée au dépôt et à la diffusion de documents scientifiques de niveau recherche, publiés ou non, émanant des établissements d'enseignement et de recherche français ou étrangers, des laboratoires publics ou privés. 


\section{Linking demographic responses and life history tactics from}

\section{2 longitudinal data in mammals}

4 Marlène Gamelon ${ }^{1,2,3,4}$, Jean-Michel Gaillard ${ }^{1}$, Olivier Gimenez ${ }^{3}$, Tim Coulson ${ }^{5}$, Shripad $5 \quad$ Tuljapurkar $^{6}$, Serge Brandt ${ }^{2}$, and Eric Baubet ${ }^{2}$

7 1. Université de Lyon, F-69000, Lyon ; Université Lyon 1 ; CNRS, UMR 5558, Laboratoire 8 de Biométrie et Biologie Evolutive, F-69622, Villeurbanne, France

9 2. Office National de la Chasse et de la Faune Sauvage, CNERA Cervidés Sangliers, 2 Bis Rue des Religieuses, BP 19, 52120 Châteauvillain, France

3. Centre d'Ecologie Fonctionnelle et Evolutive, UMR 5175, campus CNRS, 1919 route de Mende, 34293 Montpellier Cedex 5, France

4. marlene.gamelon@univ-lyon1.fr, corresponding author

5. Department of Life Sciences, Imperial College London, Silwood Park SL5 7PY, UK

6. Biological Sciences, Stanford University, Stanford, CA 94305, USA

Running headline: Stochastic elasticity and life history 


\section{Summary}

1. In stochastic environments, demographic parameters such as survival or reproduction fluctuate from year to year, leading to changes in age structure. The change observed in a given demographic parameter can thus influence population growth rate either directly or via the resulting change in age structure. Therefore, stochastic elasticity includes both the effect directly due to changing the focal demographic parameter and the effect indirectly due to changes in age structure generated by changing the focal demographic parameter.

2. We investigated the role of life history traits for driving the relative contributions of direct and indirect components of stochastic elasticity. We assessed stochastic elasticity patterns in several mammalian species with contrasted life histories.

3. The relative contribution of direct and indirect impacts of changing yearling survival was strongly associated with generation time and each of its components (i.e., age at first reproduction and life expectancy), showing that stochastic elasticity patterns are shaped by life-history tactics. For fast species, the change in population structure resulting from a change in yearling survival leads to a positive contribution to population growth rate whereas for slow species, the change in population structure resulting from a change in yearling survival leads to a negative contribution to population growth rate.

4. Irrespective of the species' pace of life, the change in population structure resulting from a change in adult survival (i.e., the indirect effect) leads to on average, a positive contribution to population growth rate.

5. In a stochastic world, analyses of stochastic elasticity improve our understanding of population dynamics in fast and slow species. These results demonstrate that the pace of life 
of a given species dictates the pathways by which observed variation in demographic parameters influence population growth.

47

48 Key-words: Generation time, life-history, mammals, population structure, stochastic 49 elasticity

50

51

52

53

54

55

56

57

58

59

60

61

62

63 


\section{Introduction}

To study population dynamics, demographic parameters such as age-specific survival and reproduction can be integrated into population models, also called population projection matrices (Caswell 2001). Sensitivity analyses can then be performed using different scales of changes to allow identifying demographic parameters that drive population dynamics. Among them, elasticity analyses are often performed in ecology and evolution to quantify the relative changes in population growth rate resulting from small relative changes in the matrix transition elements (de Kroon, van Groenendael \& Ehrlen 2000). In evolutionary biology, they are useful tools to evaluate the strength of natural (Van Tienderen 2000; Coulson et al. 2003 for an application on red deer Cervus elaphus) or human-induced (see Gamelon et al. 2011 for an application on wild boar Sus scrofa scrofa) selection on phenotypic traits.

Demographic analyses can be performed either in a deterministic or in a stochastic context. In deterministic models, demographic parameters are assumed to be constant through time and the single transition matrix only includes the mean values of demographic parameters estimated throughout the study period. The elasticity of each parameter in the average transition matrix then measures the relative change in population growth rate resulting from a very small relative change in the parameter. However, lots of studies have pointed out that including temporal variation in demographic parameters can change the picture (Tuljapurkar 1989; Boyce et al. 2006; Morris et al. 2008; Morris et al. 2011). In stochastic environments, demographic parameters fluctuate from year to year so that the transition matrix changes from year to year (Fieberg \& Ellner 2001; Boyce et al. 2006), leading the age structure to change from year to year as well (Coulson, Rohani \& Pascual 2004). Consequently, in a stochastic world, the change in a demographic parameter impacts population growth using two different pathways. As observed in the deterministic context, changing a demographic parameter has a direct effect on population growth rate. In addition, in a stochastic world, changing a 
demographic parameter will also lead to change the age structure, which will have an indirect effect on population growth rate. The total impact of changing a demographic rate on population growth thus corresponds to the sum of these direct and indirect effects (Haridas, Tuljapurkar \& Coulson 2009).

How to calculate these two components has been shown by Haridas et al. (2009) using red deer as an illustration. As expected for a long-lived species like red deer, which displays only little temporal variation in most demographic parameters (Benton \& Grant 1996), Haridas et al. (2009) found that most changes in population growth were generated by the direct effects of changing demographic parameters, with very little influence of indirect effects of changing age structure despite clear observed variation in age structure among years (Coulson et al. 2004). This pioneer study left several questions unanswered. In particular, whether the relative contribution of direct and indirect effects of changing a demographic parameter on population growth rate is constant or varies among species with contrasted life histories remains unknown. In this study, we aim to answer this question by quantifying the relative contribution of direct and indirect effects of changing a parameter on population growth in a range of mammalian populations with contrasted life histories.

More specifically, we looked for the influence of generation time. This metric provides a suitable measure of the ranking of a species on the so-called slow-fast continuum (Gaillard $e t$ al. 2005) that opposes species with an early maturity, a high fecundity, and a short life span to species with opposite characteristics (Eisenberg 1981; Gaillard et al. 1989; Read \& Harvey 1989; Promislow \& Harvey 1990). A different contribution of direct and indirect effects of changing a demographic parameter on population growth can indeed be expected among mammals with contrasting pace of life. In populations with a short generation time that live on the fast line, the contribution of indirect effects on population growth rate via changes in age structure is expected to be higher than in populations with a long generation time that live 
114 on the slow line. Increasing the proportion of juveniles in a population with a short generation

115 time is then expected to influence population growth rate to a larger extent than doing the

116 same in a population with a long generation time. To test this hypothesis, we measured the

117 elasticity patterns in 14 populations belonging to 11 mammalian species with contrasting life

118 histories.

119

120

121

122

123

124

125

126

127

128

129

130

131

132 


\section{Materials and methods}

134

135

136

137

138

139

140

141

142

143

144

145

\section{TRANSITION MATRICES}

We gathered yearly estimates of age-specific survival and reproduction from 14 populations belonging to 11 mammalian species (Table 1) ranging widely along the fast-slow continuum of life-history tactics (Gaillard et al. 2005). For each population, estimates of demographic parameters were integrated in a female age-structured population model (Caswell 2001) based on year-specific matrices. We considered a pre-breeding census model (see matrices in Appendix S1). For the mountain goat Oreamnos americanus for example, ten age-classes were used to describe its life cycle (Festa-Bianchet \& Côté 2008). The first age class corresponded to individuals of 1 year of age, the second age class to individuals of 2 years of age, the third age class to individuals of 3 years of age... and the tenth age class to individuals older than 10 years of age. The transition matrix for a given year $t$ took thus the following form:

$$
\left(\begin{array}{cccccccccc}
0 & 0 & R 3 & R 4 & R 5 & R 6 & R 7 & R 8 & R 9 & R 10 \\
S 1 & 0 & 0 & 0 & 0 & 0 & 0 & 0 & 0 & 0 \\
0 & S 2 & 0 & 0 & 0 & 0 & 0 & 0 & 0 & 0 \\
0 & 0 & S 3 & 0 & 0 & 0 & 0 & 0 & 0 & 0 \\
0 & 0 & 0 & S 4 & 0 & 0 & 0 & 0 & 0 & 0 \\
0 & 0 & 0 & 0 & S 5 & 0 & 0 & 0 & 0 & 0 \\
0 & 0 & 0 & 0 & 0 & S 6 & 0 & 0 & 0 & 0 \\
0 & 0 & 0 & 0 & 0 & 0 & S 7 & 0 & 0 & 0 \\
0 & 0 & 0 & 0 & 0 & 0 & 0 & S 8 & 0 & 0 \\
0 & 0 & 0 & 0 & 0 & 0 & 0 & 0 & S 9 & S 10
\end{array}\right)
$$


with $R$ corresponding to age class-specific recruitment and $S$ corresponding to age class-

specific survival. From the transition matrix $A_{l}$ at time 1 , we calculated the stable age

distribution denoted $W_{0}$. Then, for each year $t$, the vector of age distribution $W_{t}$ was calculated such as $W_{t}=A_{t^{*}} W_{t-1}$, then normalized (i.e., whose elements add to 1).

151

152

153

154

155

From a biological viewpoint, we defined three life history stages, with yearling survival $(\boldsymbol{\psi} l)$; survival of immature individuals $(\boldsymbol{\Psi} 2)$ older than 2 years that were not yet able to reproduce (this parameter corresponded to a different number of years depending on the life cycle of the species, going from 0 when yearling were able to reproduce (like eg., wild boar) to 8 years in primates for which females do not reproduce before 9 years of age); and adult survival ( $\left.\boldsymbol{\Psi}_{3}\right)$ corresponding to individuals that are able to reproduce (see matrices in Appendix S1). For example, for the mountain goat, the transition matrix for a given year $t$ took thus the following form:

$$
\left(\begin{array}{cccccccccc}
0 & 0 & R & R & R & R & R & R & R & R \\
\Psi_{1} & 0 & 0 & 0 & 0 & 0 & 0 & 0 & 0 & 0 \\
0 & \Psi_{2} & 0 & 0 & 0 & 0 & 0 & 0 & 0 & 0 \\
0 & 0 & \Psi_{3} & 0 & 0 & 0 & 0 & 0 & 0 & 0 \\
0 & 0 & 0 & \Psi_{3} & 0 & 0 & 0 & 0 & 0 & 0 \\
0 & 0 & 0 & 0 & \Psi_{3} & 0 & 0 & 0 & 0 & 0 \\
0 & 0 & 0 & 0 & 0 & \Psi_{3} & 0 & 0 & 0 & 0 \\
0 & 0 & 0 & 0 & 0 & 0 & \Psi_{3} & 0 & 0 & 0 \\
0 & 0 & 0 & 0 & 0 & 0 & 0 & \Psi_{3} & 0 & 0 \\
0 & 0 & 0 & 0 & 0 & 0 & 0 & 0 & \Psi_{3} & \Psi_{3}
\end{array}\right)
$$

Moreover, for each population, we calculated generation time $T b$, which corresponds to the mean age of the mothers at childbirth in the population and is defined as $T b=\sum_{i} i * S i * m i *$ 
$\lambda^{-i}$ with $S i$ the probability of surviving from birth to age $i, m i$ the number of offspring females born to a female of age $i$ and $\lambda$ the asymptotic growth rate (Leslie 1966). For each population, we also took the information about the age at first reproduction into account and estimated adult survival as the mean survival of individuals from the age at first reproduction onwards $\Psi 3$.

\section{ELASTICITIES ESTIMATES}

From these transition matrices, we measured both the direct effect of changing a demographic rate on population growth (denoted $e_{R, t}$ ) and the indirect effect via changes in age-structure (denoted $e_{U, t}$ ) (Table 2) using the procedure described by Haridas et al. (2009) in Matlab (Matlab version 7.11 2011). Haridas et al. (2009) defined annual elasticities $E_{t}$ as the sum of $e_{R, t}$ and $e_{U, t}$. Here, we defined global elasticities $E_{t}$, as the sum of $e_{R, t}$ and $\left|e_{U, t}\right|$ as $e_{U, t}$ could be positive or negative.

We thus estimated $e_{R, t}$ and $E_{t}$, for $\boldsymbol{\psi} 1$ and $\boldsymbol{\psi}_{3}$ only (i.e., not for $\boldsymbol{\psi}_{2}$ ) because this last stage was not present in some species that did reproduce as yearling. More precisely, for $\boldsymbol{\psi} 1$, we estimated the mean of $e_{R, t}$ and the mean of $E_{t}$ 'over the course of the study for the yearling survival $(\boldsymbol{\mu l})$. We calculated the ratio between the mean of $e_{R, t}$ and the mean of $E_{t}{ }^{\prime}$ to measure the relative contribution of the direct effects on population growth (i.e., caused by changing the focal demographic parameter). The division by $E_{t}$, took into account the fact that total elasticity of $\boldsymbol{\Psi}$ l could differ from one species to another. Consequently, the division by $E_{t}$, provided a way to standardize the measure of the contribution among different life histories, and thereby allowed comparing of the contribution of direct effects among populations with contrasted life histories. We performed the same analysis on survival of 
matures $(\boldsymbol{\Psi} 3)$ by summing $e_{R, t}\left(\right.$ respectively $E_{t}$ ) of all the matrix elements containing $\boldsymbol{\psi} 3$ for each time $t$. Then, we estimated the mean of $e_{R, t}$ and the mean of $E_{t^{\prime}}$ over the course of the study for $\boldsymbol{\Psi} 3$ and calculated the ratio between these two means (i.e., the ratio $e_{R, t} / E_{t^{\prime}}$ ).

\section{THE ROLE OF GENERATION TIME AND ITS COMPONENTS ON STOCHASTIC}

\section{ELASTICITY PATTERNS}

To test a potential influence of generation time and its components on the relative contribution of direct effect of changing a demographic parameter on population growth, we assessed the relationship between the species-specific ratio between $e_{R, t}$ and $E_{t}$, and generation time, for both yearling and adult survival which correspond to $\boldsymbol{\Psi} 1$ and $\boldsymbol{\Psi}$. We also assessed the relationship between the species-specific ratio between $e_{R, t}$ and $E_{t}$, and the two biological components of generation time, namely survival and reproduction. We used adult survival and age at first reproduction, respectively, to analyze these components. Our choice was motivated by the current state of art of our knowledge of life history evolution. A slower life history, characterized by a long generation time, is commonly associated with delayed reproduction and high adult survival (Stearns 1992), and both age at first reproduction (Cole 1954) and adult survival (Charnov 1986) have been shown to play a major role in shaping life history strategies. To be expressed as a biological time, adult survival was logit-transformed and interpreted as a life expectancy expressed in years (Stearns 1983, Gaillard et al. 1989). Generation time and age at first reproduction are already biological times expressed in years and therefore were only log-transformed in the analyses to satisfy the rules of allometry (Houle et al. 2011).

In addition, for each population, we studied the sign of the average $e_{U, t}$ corresponding to the component of stochastic elasticity due to change in population structure (i.e., the indirect 
209 effect). When $e_{U, t}$ is in average positive, the change in population structure resulting for a

210 change in a demographic parameter leads to a positive contribution to population growth rate.

211 On the contrary, when $e_{U, t}$ is in average negative, the change in population structure resulting

212 for a change in a demographic parameter leads to a negative contribution to population

213 growth rate.

214 These analyses were performed with R 2.12.2 (R Development Core Team 2011). 


\section{Results}

THE ROLE OF GENERATION TIME, AGE AT FIRST REPRODUCTION AND LIFE EXPECTANCY ON STOCHASTIC ELASTICITY PATTERNS

A large range of generation time, age at first reproduction and adult survival was observed across mammalian species included in the analyses (Table 1). The relationship between the ratio $e_{R, t} / E_{t}$, for yearling survival $\boldsymbol{\psi}_{1}$ and generation time (on a log-scale) (Fig. 1a) showed the longer the generation time, the lower the ratio $e_{R, t} / E_{t}$, (slope=-0.062 (SE: 0.0139), pvalue $<<0.01)$ meaning that the relative contribution of $e_{R, t}$ to the population growth rate decreases with the generation time. The relationship between the ratio $e_{R, t} / E_{t}$, for yearling survival $\boldsymbol{\Psi}$ and age at first reproduction (on a log-scale) (Fig. 2a) showed the later the age at first reproduction, the lower the ratio $e_{R, t} / E_{t}$, (slope= $-0.060(\mathrm{SE}: 0.0138), \mathrm{p}$-value $\left.<<0.01\right)$ meaning that the relative contribution of $e_{R, t}$ to the population growth rate decreases with the age at first reproduction. Finally, the relationship between the ratio $e_{R, t} / E_{t}$, for yearling survival $\boldsymbol{\Psi}$ l and life expectancy (i.e., adult survival on a logit-scale) (Fig. 3a) showed the higher the life expectancy, the lower the ratio $e_{R, t} / E_{t}$, (slope= -0.038 (SE: 0.0148), p-value $=$ $0.025)$ meaning that the relative contribution of $e_{R, t}$ to the population growth rate decreases with the life expectancy.

By studying the sign of the average $e_{U, t}$ allows distinguishing two groups of species. A first group of species characterized by a fast pace of life, with a short generation time, an early age at first reproduction, and a low adult survival, had a positive $e_{U, t}$ on average for yearling survival $\boldsymbol{\Psi}$ l. For these species, the change in population structure resulting from a change in yearling survival leads to a positive contribution to population growth rate. The second group of species were characterized by a slow pace of life, with a long generation time, a late age at first reproduction and a high adult survival, had a negative $e_{U, t}$ on average yearling 
survival $\boldsymbol{\Psi}$ l. For these species, the change in population structure resulting for a change in a yearling survival leads to a negative contribution to population growth rate.

No relationship was found between the ratio $e_{R, t} / E_{t}$, for adult survival $\boldsymbol{\psi}_{3}$ and generation time (on a log-scale) (Fig. 1b), age at first reproduction (on a log-scale) (Fig. 2b) and life expectancy (Fig. 3b). For all species, the relative contribution of $e_{R, t}$ to the population growth rate is thus similar. By studying the sign of the average $e_{U, t}$, we found that all species had a positive $e_{U, t}$ on average for adult survival $\Psi 3$ irrespective of their pace of life, except red squirrel that exhibited a negative $e_{U, t}$ on average. On average, for all species except red squirrel, the change in population structure resulting from a change in adult survival leads to a positive contribution to population growth rate.

(1)

(1)




\section{STOCHASTIC VS. DETERMINISTIC ELASTICITIES}

Classically, in demographic analyses, deterministic elasticity are used to quantify the effect on population growth rate of a proportional change in a given fitness component (de Kroon et al. 1986). For species characterized by a fast pace of life, elasticity of yearling survival is generally higher than that of adult survival. For instance, in a heavily hunted wild boar population characterized by a short generation time of 2.3 years, elasticity of yearling survival is higher than that of adult survival (Servanty et al. 2011; Gamelon et al. 2011), meaning that population growth rate in fast species is much more sensitive to a given variation in yearling survival than to the same relative variation in adult survival. On the contrary, in large herbivores, i.e. for species characterized by a slow pace of life, these deterministic analyses reveal that the elasticity of adult survival is higher than that of yearling survival (Gaillard $e t$ al. 2000). For these species, adult survival thus drives the demography of the population. Indeed, in ungulate females for instance, females skip a reproductive event instead of jeopardizing their own survival (Gaillard \& Yoccoz 2003). Population growth rate in slow species is much more sensitive to a given variation in adult survival than to the same relative variation in yearling survival.

These deterministic elasticities usually estimated in demographic analyses, are based on the average transition matrix and correspond to $e_{R, t}$, the direct effect of changing a given demographic parameter on population growth rate. Nevertheless, in stochastic environments, demographic parameters fluctuate from year to year. In the bighorn sheep population of Sheep River for instance (Coulson et al. 2005), adult survival is variable from year to year because of pneumonia and predation (Festa-Bianchet 1988; Jorgenson et al. 1997; Ross et al. 1997), leading to change in the age structure. In addition to $e_{R, t}$, stochastic elasticity allows estimating 
$e_{U, t}$, the indirect effect of changing a given demographic parameter on population growth rate, via the change in population structure. Analyses of stochastic elasticity thus improve our understanding of population dynamics in fast and slow species in a stochastic world.

\section{FAST SPECIES AND STOCHASTIC ELASTICITY PATTERNS}

The mean ratio $e_{R, t} / E_{t}$, provided a simple metric to evaluate the relative contribution of the direct effects of changing a given demographic parameter on population growth rate, which is standardized across species when life cycle are defined on a similar basis. For species characterized by a fast pace of life, increasing yearling survival $\boldsymbol{\Psi} 1$ increased the proportion of yearlings in the population that are able to recruit, as for instance in wild boar being able to reproduce at 1 year of age (Servanty et al. 2011). Consequently, the change in population structure resulting from a change in yearling survival leads to a positive contribution to population growth rate.

\section{SLOW SPECIES AND STOCHASTIC ELASTICITY PATTERNS}

On the contrary, for species characterized by a slow pace of life, increasing yearling survival $\boldsymbol{\Psi} l$ increased the proportion of yearlings in these slow populations as it does in fast ones, but individuals will not recruit before 3 years of age or more. For instance, in the white rhinoceros Ceratotherium simens, reproduction starts at 6 years of age (Owen-Smith 1988).

Consequently, increasing yearling survival in rhinoceros would increase the population growth rate only via direct way, because individuals less than 1 year of age are not able to reproduce thus explaining why $e_{U, t}$ was negative for slow species. In other words, the change in population structure due to an increase of yearling survival will negatively contribute to 
population growth rate for species characterized by a slow pace of life. More precisely, the slower the species, the stronger the negative contribution of indirect effect due to change in yearling survival on population growth rate. This result provides further support for the theory of "malediction of long-lived species" (Lebreton 2006) predicting higher extinction rates for long-lived species.

The relative contribution of direct vs. indirect effects of changing adult survival $\boldsymbol{\Psi}_{3}$ on population growth was not associated with either generation time, age at first reproduction, or life expectancy. Irrespective of their pace of life, all species but red squirrel showed identical relative contributions of direct vs. indirect effects of changing adult survival on population growth. Increasing $\boldsymbol{\Psi} 3$ in a given population increased the proportion of adult individuals that are able to reproduce. Consequently, the contribution of indirect effect of an increase of adult survival to long-term population growth was positive. In the same way, decreasing survival of prime-aged females will lead to decrease the population growth rate by the direct way but also by the indirect way and such a decrease could thus affect population viability. As already reported, size-selective harvesting, where the largest and thus the prime-aged individuals are preferentially taken, in both marine and terrestrial habitats can affect the demography of populations (Fenberg \& Roy 2008). This analysis of stochastic elasticity patterns provides further support of that size-selective harvesting can negatively influence the demography of populations irrespective of their pace of life. 
343 This work was supported by the French National Agency for Wildlife (ONCFS). We warmly

344 thank Rob Salguero-Gómez and Douglas Morris for their helpful comments on a previous 345 draft.

346

347 


\section{References}

Benton, T. G. \& Grant, A. (1996) How to keep fit in the real world: Elasticity analyses and selection pressures on life histories in a variable environment. American Naturalist, 147, 115139.

Boyce, M. S., Haridas, C. V., Lee, C. T., Boggs, C., Bruna, E. \& Coulson, T. (2006)

Demography in an increasingly variable world. Trends in Ecology \& Evolution, 21, 141-148.

Caswell, H. (2001) Matrix population models. 2nd ed. Sinauer, MA.

Charnov, E. L. (1986) Life history evolution in a "recruitment population": Why are adult mortality rates constant? Oikos, 47, 129-134.

Cole, L. M. C. (1954) Some features of random population cycles. The Journal of Wildlife Management, 18, 2-24.

Coulson, T., Gaillard, J.-M. \& Festa-Bianchet, M. (2005) Decomposing the variation in population growth into contributions from multiple demographic rates. Journal of Animal Ecology, 74, 789-801.

Coulson, T., Kruuk, L. E. B., Tavecchia, G., Pemberton, J. M. \& Clutton-Brock, T. H. (2003) Estimating selection on neonatal traits in red deer using elasticity path analysis. Evolution, 57, 2879-2892.

Coulson, T., Rohani, P. \& Pascual, M. (2004) Skeletons, noise and population growth: the end of an old debate? Trends in Ecology \& Evolution, 19, 359-364.

Descamps, S. (2006) Stratégies d'histoire de vie dans une population d'écureuils roux d'Amérique du Nord. Master's thesis, Université du Québec à Rimouski - Université Claude 
Bernard Lyon 1.

Eisenberg, J.F. (1981) The Mammalian Radiation. Athlone Press, London.

Fenberg, P. B. \& Roy, K. (2008) Ecological and evolutionary consequences of size-selective harvesting: how much do we know? Molecular Ecology, 17, 209-220.

Festa-Bianchet, M. (1988) A pneumonia epizootic in bighorn sheep, with comments on preventive management. Proceedings of the Northern Wild Sheep and Goat Council, 6, 66-76.

Festa-Bianchet, M. \& Côté, S. D. (2008) Mountain goats: ecology, behavior, and conservation of an alpine ungulate. Island Press, Washington, DC.

Fieberg, J. \& Ellner, S. P. (2001) Stochastic matrix models for conservation biology: a comparative review of methods. Ecology Letters, 4, 244-266.

Gaillard, J.-M., Yoccoz, N. G., Lebreton, J.-D., Bonenfant, C., Devillard, S., Loison, A., Pontier, D. \& Allaine, D. (2005) Generation time: A reliable metric to measure life-history variation among mammalian populations. American Naturalist, 166, 119-123.

Gaillard, J.-M., Pontier, D., Allaine, D., Lebreton, J.D., Trouvilliez, J. \& Clobert, J. (1989) An analysis of demographic tactics in birds and mammals. Oikos, 56, 59-76.

Gaillard, J.-M., Festa-Bianchet, M., Yoccoz, N. G., Loison, A. \& Toїgo, C. (2000) Temporal variation in fitness components and population dynamics of large herbivores. Annual Review of Ecological Systems, 31, 367-393.

Gaillard, J.-M. \& Yoccoz, N. G. (2003) Temporal variation in survival of mammals: a case of environmental canalization? Ecology, 84, 3294-3306.

Gamelon, M., Besnard, A., Gaillard, J.-M., Servanty, S., Baubet, E., Brandt, S. \& Gimenez, 
390

391

392

393

394

395

396

397

398

399

400

401

402

403

404

405

406

407

408

409

410

O. (2011) High hunting pressure selects for earlier birth date: wild boar as a case study.

Evolution, 65, 3100-3112.

Haridas, C. V., Tuljapurkar, S. \& Coulson, T. (2009) Estimating stochastic elasticities directly from longitudinal data. Ecology letters, 12, 806-812.

Houle, D., Pélabon, C., Wagner, G. P. \& Hansen, T. (2011) Measurement and meaning in biology. The Quarterly Review of Biology, 86, 3-34.

Jorgenson, J. T., Festa-Bianchet, M., Gaillard, J. M. \& Wishart, W. D. (1997) Effects of age, sex, disease, and density on survival of bighorn sheep. Ecology, 78, 1019-1032.

de Kroon, H., Plaisier, A., van Groenendael, J. \& Caswell, H. (1986) Elasticity: the relative contribution of demographic parameters to population growth rate. Ecology, 67, 1427-1431.

de Kroon, H., van Groenendael, J. \& Ehrlen, J. (2000) Elasticities: A review of methods and model limitations. Ecology, 81, 607-618.

Lebreton, J.-D. (2006) Dynamical and statistical models of vertebrate population dynamics. Comptes Rendus Biologies, 329, 804-812.

Leslie, P. H. (1966) The intrinsic rate of increase and the overlap of successive generations in a population of guillemots (Uria aalge pont.). Journal of Animal Ecology, 35, 291-301.

Matlab version 7.11 2011. The Mathworks. Nantick, Massachusetts, USA.

Morris, W. F., Altmann, J., Brockman, D. K., Cords, M., Fedigan, L. M., Pusey, A. E., Stoinski, T. S., Bronikowski, A. M., Alberts, S. C. \& Strier, K. B. (2011) Low demographic variability in wild primate populations: fitness impacts of variation, covariation, and serial correlation in vital rates. The American Naturalist, 177, E14-E28. 
Morris, W. F., Pfister, C. A., Tuljapurkar, S., Haridas, C. V., Boggs, C. L., Boyce, M. S.,

Bruna, E. M., Church, D. R., Coulson, T., Doak, D. F. et al. (2008) Longevity can buffer plant

Owen-Smith, R. N. (1988) Megaherbivores: the influence of very large body size on ecology.

Promislow, D.E.L. \& Harvey, P.H. (1990) Living fast and dying young: a comparative analysis of life-history variation among mammals. Journal of Zoology, 220, 417-437.

R Development Core Team 2011. R: A language and environment for statistical computing. R Foundation for Statistical Computing, Vienna, Austria.

Read, A.F. \& Harvey, P.H. (1989) Life-history differences among the eutherian radiations. Journal of Zoology, 219, 329-353.

Ross, P. I., Jalkotzy, M. G. \& Festa-Bianchet, M. (1997) Cougar predation on bighorn sheep in southwestern Alberta during winter. Canadian Journal of Zoology, 75, 771-775. Influence of harvesting pressure on demographic tactics: implications for wildlife management. Journal of Applied Ecology, 48, 835-843.

Stearns, S. C. (1983) The influence of size and phylogeny on patterns of covariation among life-history traits in the mammals. Oikos, 41, 173-187.

Stearns, S. C. (1992) The evolution of life histories. vol. 248. Oxford University Press Oxford. 
432 dynamics. Ecology, 81, 666-679.

433 Tuljapurkar, S. (1989) An uncertain life: Demography in random environments. Theoretical 434 Population Biology, 35, 227-294.

435

436

437

438

439

440

441 
Table 1. Mammal populations for which yearly estimates of age-specific survival and reproduction were available and their associated generation time, age at first reproduction (in years) and adult survival. Two different populations of roe deer (1: Trois-Fontaines and 2: Chizé) and bighorn sheep (1: Ram Mountain and 2: Sheep River) were included in the analyses.

\begin{tabular}{|c|c|c|c|c|c|}
\hline Population & $\begin{array}{l}\text { Study } \\
\text { period }\end{array}$ & Reference & $\begin{array}{l}\text { Generation } \\
\text { time }\end{array}$ & $\begin{array}{l}\text { Age at first } \\
\text { reproduction }\end{array}$ & $\begin{array}{c}\text { Adult } \\
\text { survival }\end{array}$ \\
\hline 1. Wild boar (Sus scrofa scrofa) & 1983-2005 & This study & 2.65 & 1 & 0.458 \\
\hline 2. Red squirrel (Tamiasciurus hudsonicus) & $1990-2003$ & Descamps et al. 2006 & 2.86 & 1 & 0.512 \\
\hline 3. Roe deer 1 (Capreolus capreolus) & 1985-1998 & Gaillard et al. 2003 & 4.33 & 2 & 0.899 \\
\hline 4. Roe deer 2 (Capreolus capreolus) & 1985-1998 & Gaillard et al. 2003 & 5.21 & 2 & 0.923 \\
\hline 5. Bighorn sheep 1 (Ovis Canadensis) & 1980-1995 & $\begin{array}{l}\text { Coulson, Gaillard \& Festa- } \\
\text { Bianchet } 2005\end{array}$ & 7.55 & 2 & 0.926 \\
\hline 6. Bighorn sheep 2 (Ovis Canadensis) & 1983-1997 & $\begin{array}{l}\text { Coulson, Gaillard \& Festa- } \\
\text { Bianchet } 2005\end{array}$ & 7.72 & 2 & 0.896 \\
\hline 7. Mountain goat (Oreamnos americanus) & 1992-2002 & Festa-Bianchet \& Côté 2008 & 8.75 & 3 & 0.933 \\
\hline 8. Yellow baboon (Papio cynocephalus) & $1971-2007$ & Morris et al. 2011 & 16.45 & 7 & 0.920 \\
\hline 9. Blue monkey (Cercopithecus mitis stuhlmanni) & $1980-2007$ & Morris et al. 2011 & 18.05 & 8 & 0.952 \\
\hline 10. Northern muriqui (Brachyteles hypoxanthus) & $1983-2007$ & Morris et al. 2011 & 22.07 & 9 & 0.969 \\
\hline 11. White-faced capuchin monkey (Cebus capucinus) & 1986-2007 & Morris et al. 2011 & 22.88 & 7 & 0.943 \\
\hline 12. Verreaux's sifaka (Propithecus verreauxi) & 1984-2007 & Morris et al. 2011 & 23.69 & 7 & 0.928 \\
\hline 13. Mountain gorilla (Gorilla beringei beringei) & $1967-2007$ & Morris et al. 2011 & 30.48 & 11 & 0.975 \\
\hline 14. Eastern chimpanzee (Pan troglodytes schweinfurthii) & $1963-2007$ & Morris et al. 2011 & 40.48 & 16 & 0.951 \\
\hline
\end{tabular}


Table 2. Parameters and their biological meaning used in the analyses.

Parameters Biological meaning

$e_{R, t} \quad$ Component of stochastic elasticity due to change in the demographic parameters: measure of the direct effect of changing a given demographic parameter on population growth rate

$e_{U, t} \quad$ Component of stochastic elasticity due to change in population structure: measure of the indirect effect of changing a given demographic parameter on population growth rate

$E_{t}$, Global elasticity corresponding to the sum of $e_{R, t}$ and $\mid e_{U, t \mid}$

$\boldsymbol{\psi} 1 \quad$ Yearling survival, i.e. survival of individuals between 1 and 2 years of age

$\boldsymbol{\Psi}$ Survival of immature individuals, i.e. yearly survival of individuals, older than 2 years that are not yet able to reproduce

43 Adult survival, i.e. yearly survival of individuals older than 2 years that are able to reproduce 
451

452

453

454

455

456

457

458

459

460

461

462

463

464

465

466

467

468

469

470

Figure 1. Relationship between the ratio $e_{R, t} / E_{t^{\prime}}$ (with $E_{t^{\prime}=} e_{R, t}+\left|e_{U, t}\right|$ ) and generation time (on a log-scale) for the 14 populations displayed in Table 1 for (a) yearling survival $\boldsymbol{\Psi}$; (b) adult survival $\boldsymbol{\Psi}$ 3. Filled circles correspond to a negative average $e_{U, t}$, closed circles correspond to a positive average $e_{U, t}$. The numbers on the graph correspond to the populations displayed in Table 1.

Figure 2. Relationship between the ratio $e_{R, t} / E_{t}$ ( with $E_{t^{\prime}=} e_{R, t}+\left|e_{U, t}\right|$ ) and the age at first reproduction (on a log-scale) for the 14 populations displayed in Table 1 for (a) yearling survival $\boldsymbol{\Psi}$; (b) adult survival $\boldsymbol{\Psi}_{3}$. Filled circles correspond to a negative average $e_{U, t}$, closed circles correspond to a positive average $e_{U, t}$. The numbers on the graph correspond to the populations displayed in Table 1.

Figure 3. Relationship between the ratio $e_{R, t} / E_{t^{\prime}}$ (with $E_{t^{\prime}}=e_{R, t}+\left|e_{U, t}\right|$ ) and the adult survival (on the logit-scale) for the 14 populations displayed in Table 1 for (a) yearling survival $\boldsymbol{\Psi}$; (b) adult survival $\boldsymbol{\Psi}$. Filled circles correspond to a negative average $e_{U, t}$, closed circles correspond to a positive average $e_{U, t}$. The numbers on the graph correspond to the populations displayed in Table 1. 
471

472

473

474

475

476

477

478

479

480

481

482

1.0

1.5

(a)

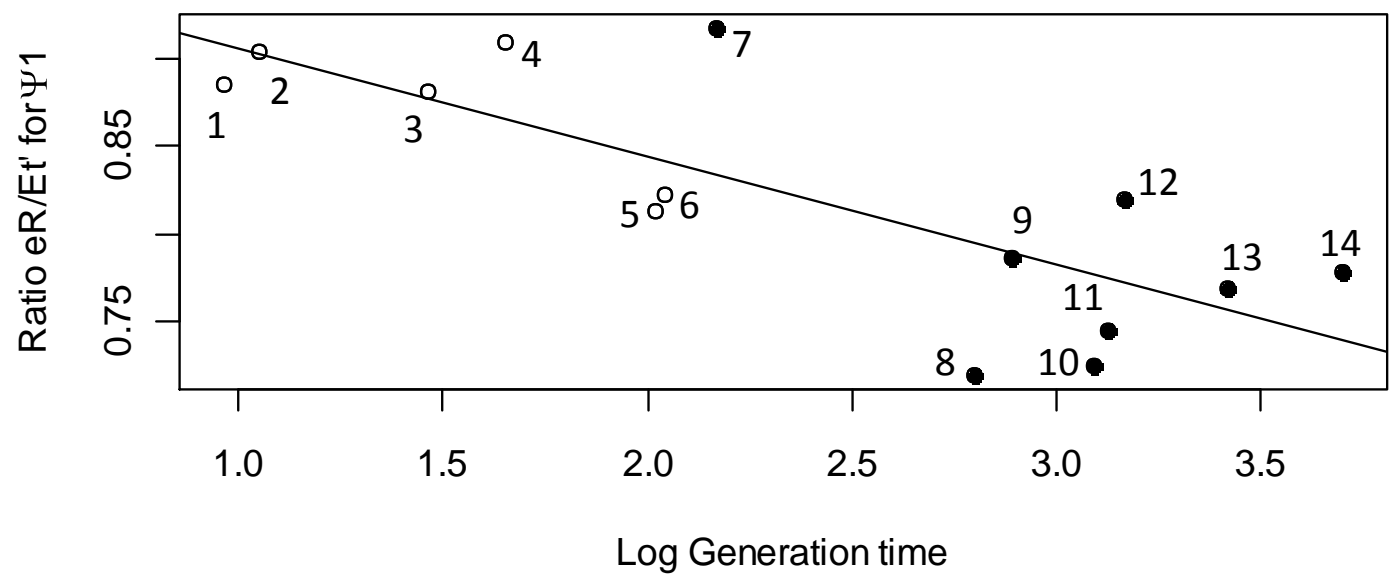

(b)

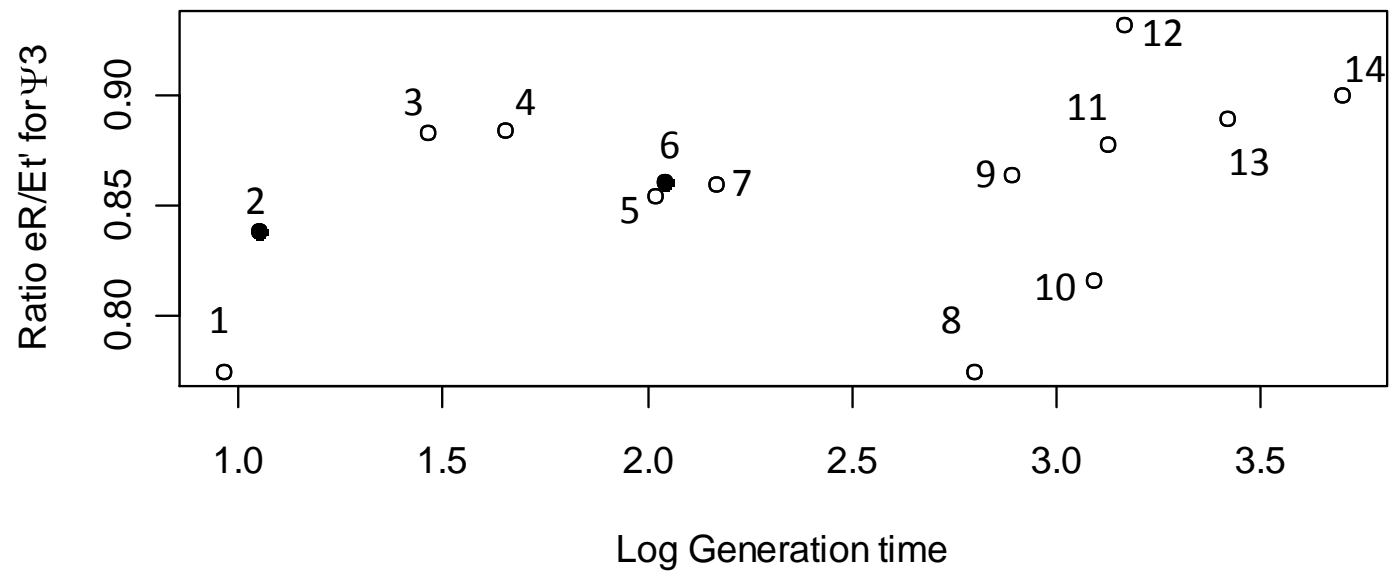

483

484

485

486

487

488 
Fig. 2.

490

(a)

491

492

493

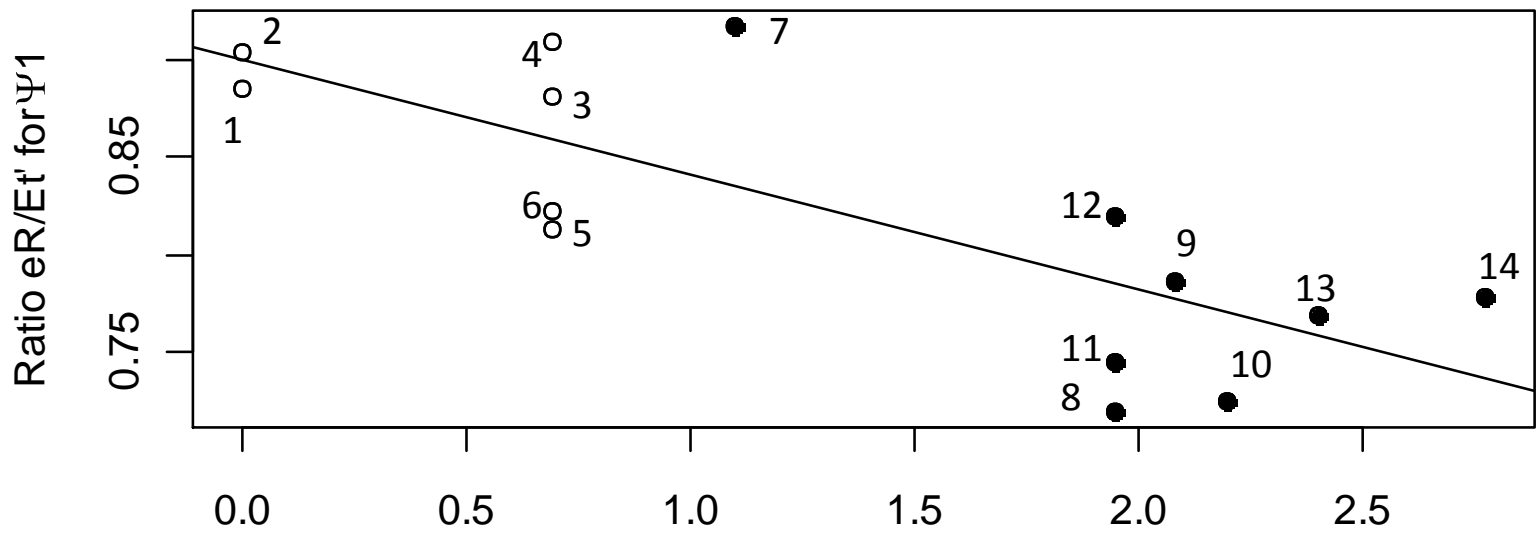

Log Age at first reproduction

495

(b)

497

498

499

500

501

502

503

504

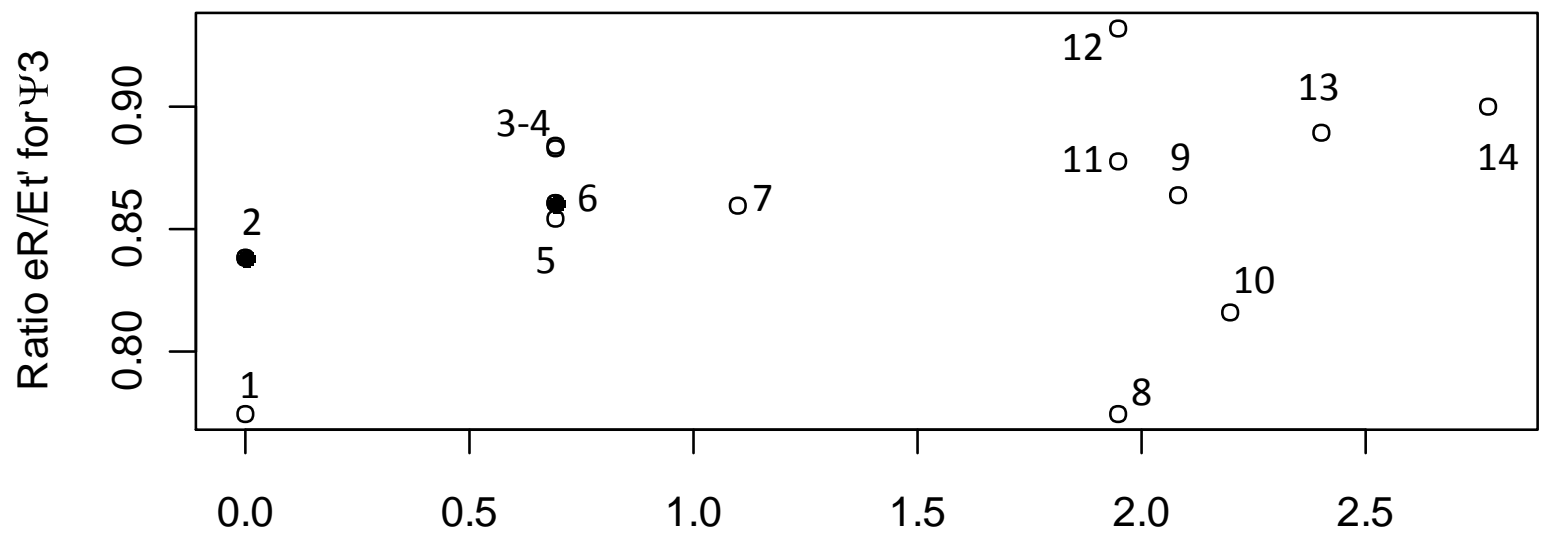

Log Age at first reproduction

505

506

507 
Fig. 3.

509

510

(a)

511

512

513

514

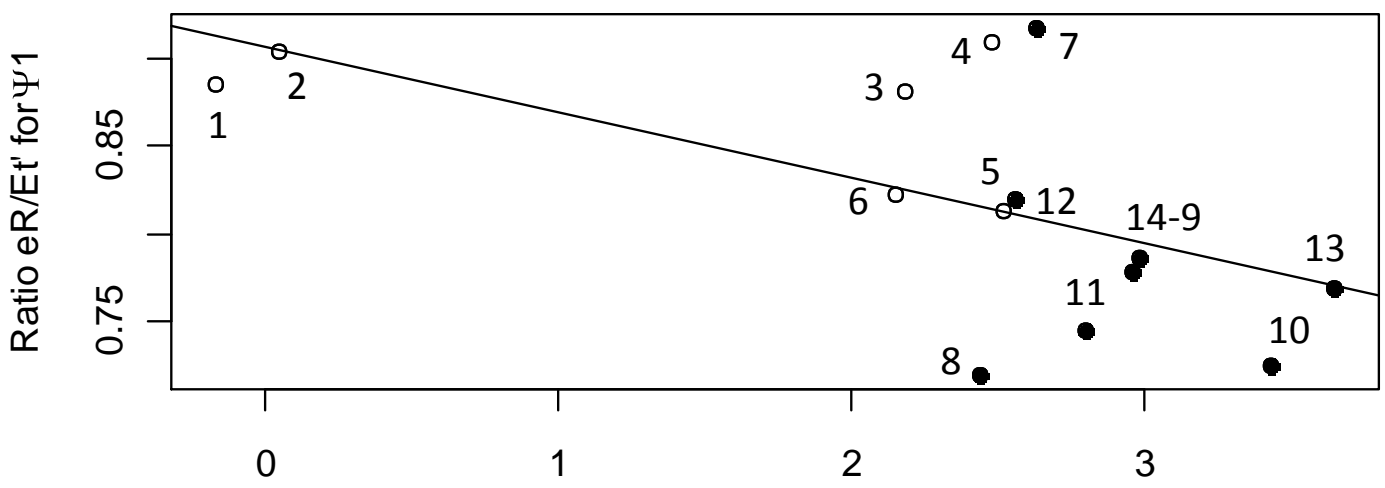

Logit (Adult survival)

516

(b)

517

518

519

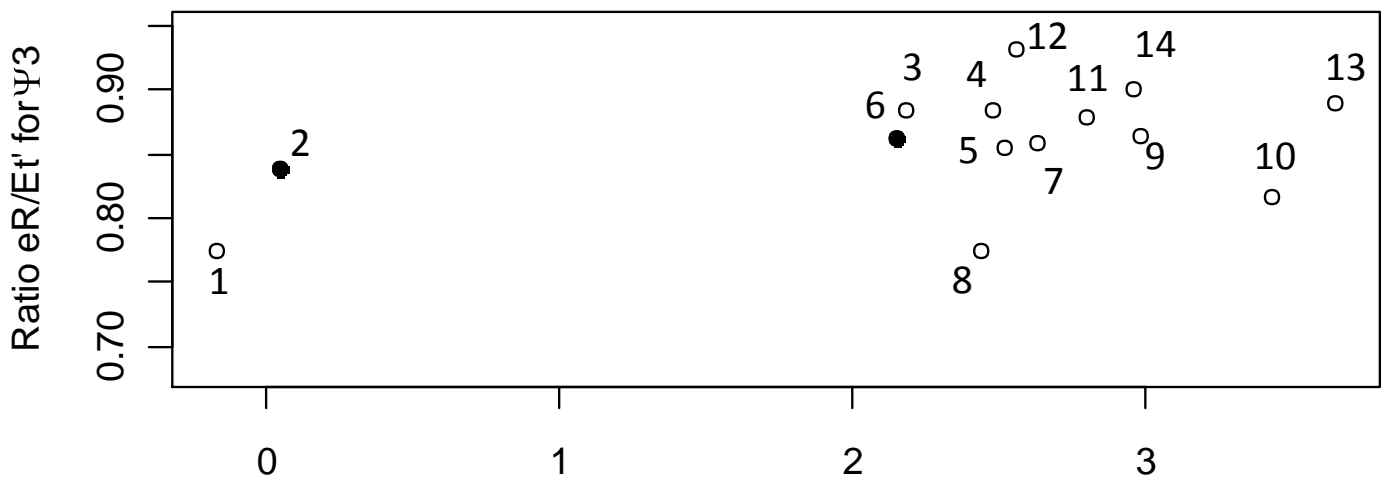

Logit (Adult survival)

521

522

523

524 